\title{
SURGICAL OUTCOME OF INFERIOR RECTUS RECESSION IN MANAGEMENT OF MONOCULAR ELEVATION DEFICIT
}

\author{
By \\ Tamer Tawheed Mohamed Abd El-Salam, Attiat Mostafa El-Sayed \\ Mostafa and Mahmmoud Mohamed Saleh \\ Department of Ophthalmology, Al-Azhar Faculty of Medicine, Cairo, Egypt \\ Corresponding Author: Tamer Tawheed Mohamed Abd El-Salam, \\ Mobile: 01280049466, E-mail: Tamer.Twheed@gmail.com
}

\begin{abstract}
Background: Monocular Elevation Deficiency (MED) is an inability to elevate one eye in all field of gazes usually resulting in one eye that is pointed downward relative to the other eye.

Objective: To evaluate the efficacy of inferior rectus recession in management of monocular elevation deficit (MED) with +ve or -ve forced duction test (FDT).

Patients and Methods: Our study was carried out on 20 patients complaining of MED who were selected from out-patients clinic in Sayed Galal and Al-Hussein University Hospitals. From January 2017 to May 2019. The patients were divided into 2 equal groups. Group A with +ve FDT, and group B with -ve FDT. Both groups had inferior rectus recession (IRR).

Results: Preoperatively, $40 \%$ of patients in group A were -4 (limited elevation), and $60 \%$ of patients were -3 . All those patients improved to -1 postoperatively. On the other hand, $90 \%$ of patients in group B were -4 , and $10 \%$ of patients were -3 (limited elevation). They improved postoperatively to -3 and -2 respectively. In group (A), the average of preoperative hypotropia was $19.40 \pm 1.43 \mathrm{PD}$. All the patients had IRR: the postoperative average of hypotropia was $1.10 \pm 1.91 \mathrm{PD}$ with average of correction $18.30 \pm 1.42 \mathrm{PD}$. In group (B) having MED with -ve FDT were operated by IRR. A reliable and effective correction of hypotropia in 7 patients with preoperative mean deviation of $19.86 \pm 1.68 \mathrm{PD}$, and postoperative mean deviation of $2.71 \pm$ $2.56 \mathrm{PD}$ with average of correction $17.14 \pm 1.86 \mathrm{PD}$. Partial correction of hypotropia in 3 patients underwent Knapp's procedure with preoperative mean deviation of $50.0 \pm 5.00$, postoperative average of correction of $18.00 \pm 0.00 \mathrm{PD}$, post Knapp procedure the deviation was $3.00 \pm 2.65$ with average of correction of $29.00 \pm$ 2.65 .
\end{abstract}

Conclusion: Although the MED is etiologically multifactorial, satisfactory surgical results can be achieved by IRR as a simple and reliable 1ry intervention for both types (+ve FDT and -ve FDT).

Keywords: Inferior rectus recession, Monocular Elevation Deficiency (MED).

\section{INTRODUCTION}

Previously MED was known as double elevator palsy, this condition may be associated with ptosis and co-existent horizontal deviation. Both paretic and restrictive causes have been found on FDT and saccadic velocity measurements. The unilateral elevation deficit may also have supranuclear etiology (Zafar et al., 2012).

Monocular elevation deficiency (MED) is classified as three subtypes: 1) Restrictive form, with features including positive forced duction test (FDT) for elevation, normal elevation force 
generation test (FGT), and elevation saccadic velocity, often an extra or deeper lower eyelid fold on attempted up gaze and poor or absent Bell's phenomenon; 2) Paretic form with elevator muscle weakness, with features including free FDT, reduced elevation FGT and saccadic velocity, in which the Bell's phenomenon is often preserved; and 3) A combination form, with features including positive FDT for elevation and reduced FGT and saccadic velocity for elevation (Talebnejad et al., 2014).

MED can be congenital or acquired. Congenital cases of MED occur sporadically and include supranuclear palsy, primary superior rectus (SR) paresis, and primary inferior rectus (IR) restriction as in cases of congenital fibrosis of inferior rectus. Acquired MED is usually caused by trauma, cerebrovascular diseases like hypertension, thromboembolism, sarcoidosis, syphilis, and midbrain tumors like pineoblastoma, acoustic neuromas and metastatic tumors affecting supranuclear pathways (Saluja and Bhari, 2019).

The pathophysiology of MED is poorly understood. The early description of this condition was thought to be due to a combination of SR and inferior oblique muscle palsy (called double elevator palsy). Studies have shown that only $30 \%$ of cases are caused by this problem, and the FDT has demonstrated that $70 \%$ is caused by IR restriction. Magnetic resonance imaging (MRI) may be a useful adjunct to saccadic velocity assessment in differentiating between primary IR restriction, primary SR paresis, and congenital supranuclear elevation deficiency (Talebnejad et al., 2014).

The first step in surgical correction of MED is to confirm the type of MED restrictive or paralytic. It was done by doing FDT (forced duction test) for inferior rectus. If FDT is positive for IR (Type 1 MED), an IR recession (IRR) with conjunctival recession is done. The eye should now elevate freely if all the adhesions and tight inferior rectus fibres have been severed. FDT is repeated after the inferior rectus was reattached. Elevation of the eye by at least 20-25 degrees should be possible. In cases of secondary IR restriction, the hypotropia persists after IRR because of primary superior rectus muscle (SR) palsy. In such cases, Knapp's procedure is described with IRR along with conjuctival recession. If vertical deviation is small, and eye was able to elevate above the midline, IR recession combined with $\mathrm{SR}$ resection can also be done (Goray, 2015).

The aim of this work was to evaluate the efficacy of inferior rectus recession in management of monocular elevation deficit (MED) with +ve or -ve forced duction test (FDT).

\section{PATIENTS AND METHODS}

Our study was carried out on 20 patients complaining of MED selected from out-patients clinic in Sayed Galal and Al-Hussein University Hospitals, from January 2017 to May 2019. The patients were able to read and give consents. The patients were divided into 2 equal groups. Group A with +ve FDT, and group B with -ve FDT. Both groups had IRR (inferior rectus recession). Patients with limited elevation above the 
horizontal line with positive or negative duction test, hypotropia, chin-up head posture and ptosis were included. Patients with complex eye motility disorders, trauma, superior oblique over action, third nerve palsy, previous strabismus surgery were excluded.

All patients were subjected to complete medical, ocular, history, complete ocular examination, and documented digital photography.

Response to treatment: patient with hypotropia < 5 PD was considered successful outcome. Ptosis surgery, if required, was performed after strabismus surgery. Any patient of both groups with post-operative residual significant hypotropia or chin-up was undergoing surgical procedure (Knapp's operation) after 6 months. Postoperative evaluation of results of surgery was recorded after one week, 1 month, 3 months and 6 months of operation.

\section{Statistical Methods:}

Data were collected, tabulated, then analyzed using IBM $\odot$ SPSS $\odot$ version 22 (IBM@ Corp., Armonk, NY). Normally, distributed numerical data were presented as mean and standard deviation (SD). Qualitative data were presented as number and percentage. Comparison of normally distributed numerical data using the unpaired Student $t$ test. Skewed data were compared using the Mann-Whitney U test. Categorical data were compared using the chi-squared test or Fisher's exact test, when appropriate. A two-sided p-value $<0.05$ were considered statistically significant.

\section{RESULTS}

In comparing between two studied groups regarding age, range of age in group A was 10-27 year versus 4-42 year in group $\mathrm{B}$, and p-value was 0.367 . Regarding sex, both groups were similar.
Regarding eye in group A, right eye was in 3 cases, and left eye in 7 cases. IN group B right eye was in 2 cases, and left eye in 8 cases. Regarding FDT, p-value was significant (Table 1).

Table (1): Comparison between the two studied groups regarding age, sex, eye and FDT

\begin{tabular}{|c|c|c|c|c|}
\hline \multirow{2}{*}{ Parameters } & Groups & Group A & Group B & \multirow{2}{*}{ P-value } \\
\cline { 2 - 4 } Age & Mean \pm SD & No. $=10$ & No. $=10$ & \\
\cline { 2 - 4 } & Range & $17.30 \pm 5.29$ & $21.30 \pm 12.60$ & \multirow{2}{*}{0.367} \\
\hline \multirow{2}{*}{ Sex } & Female & $2(20.0 \%)$ & $2(20.0 \%)$ & \multirow{2}{*}{1.000} \\
\cline { 2 - 4 } & Male & $8(80.0 \%)$ & $8(80.0 \%)$ & \multirow{2}{*}{0.606} \\
\hline \multirow{4}{*}{ FDT } & Right & $3(30.0 \%)$ & $2(20.0 \%)$ & \multirow{3}{*}{0.000} \\
\cline { 2 - 4 } & Left & $7(70.0 \%)$ & $8(80.0 \%)$ & \\
\cline { 2 - 4 } & $-4.00-$ & $0(0.0 \%)$ & $9(90.0 \%)$ & \\
\cline { 2 - 4 } & $-3.00-$ & $0(0.0 \%)$ & $0(0.0 \%)$ & \\
\cline { 2 - 4 } & 3.00 & $5(50.0 \%)$ & $0(0.0 \%)$ & \\
\hline
\end{tabular}


$P$ value of elevation was statistically significant between preoperative and

postoperative in the two groups (Table 2).

Table (2): Comparison between the two studied groups regarding elevation of the eye pre and post operative

\begin{tabular}{|c|c|c|c|c|c|c|}
\hline \multirow{2}{*}{\multicolumn{2}{|c|}{$\begin{array}{ll}\text { Elevation } & \text { Groups }\end{array}$}} & \multicolumn{2}{|c|}{ Group A } & \multicolumn{2}{|c|}{ Group B } & \multirow{2}{*}{ P-value } \\
\hline & & No. & $\%$ & No. & $\%$ & \\
\hline \multirow{4}{*}{ Pre-operative } & $-4.00-$ & 4 & $40.0 \%$ & 9 & $90.0 \%$ & \multirow{4}{*}{0.019} \\
\hline & $-3.00-$ & 6 & $60.0 \%$ & 1 & $10.0 \%$ & \\
\hline & $-2.00-$ & 0 & $0.0 \%$ & 0 & $0.0 \%$ & \\
\hline & $-1.00-$ & 0 & $0.0 \%$ & 0 & $0.0 \%$ & \\
\hline \multirow{4}{*}{ Post-operative } & $-4.00-$ & 0 & $0.0 \%$ & 0 & $0.0 \%$ & \multirow{5}{*}{$<0.001$} \\
\hline & $-3.00-$ & 0 & $0.0 \%$ & 3 & $30.0 \%$ & \\
\hline & $-2.00-$ & 0 & $0.0 \%$ & 7 & $70.0 \%$ & \\
\hline & $-1.00-$ & 10 & $100.0 \%$ & 0 & $0.0 \%$ & \\
\hline \multicolumn{2}{|c|}{ P-value } & \multicolumn{2}{|c|}{$<0.001$} & \multicolumn{2}{|c|}{0.001} & \\
\hline
\end{tabular}

Ptosis improved postoperatively in 12 cases: 7 cases in group A (70\%), and 5 cases in group B (50\%). In 8 cases, surgery was needed: 3 cases in group A $(30 \%)$, and 5 cases in group B $(50 \%)$ (Table 3).

Table (3): Comparison between the two studied groups regarding ptosis of the eye pre and postoperative

\begin{tabular}{|c|c|c|c|c|c|c|}
\hline \multirow{2}{*}{ Ptosis } & Groups & \multicolumn{2}{|c|}{ Group A } & \multicolumn{2}{c|}{ Group B } & \multirow{2}{*}{ P-value } \\
\cline { 3 - 7 } & & No. & $\mathbf{\%}$ & No. & \% & \\
\hline \multirow{3}{*}{ Pre-operative } & TRUE & 3 & $30.0 \%$ & 2 & $20.0 \%$ & \multirow{3}{*}{0.819} \\
\cline { 2 - 6 } & PSEUDO & 2 & $20.0 \%$ & 3 & $30.0 \%$ & \multirow{3}{*}{ Post-operative } \\
\cline { 2 - 6 } & TRUE + PSEUDO & 5 & $50.0 \%$ & 5 & $50.0 \%$ & \\
\cline { 2 - 6 } & Mild & 5 & $50.0 \%$ & 2 & $20.0 \%$ & \multirow{3}{*}{0.196} \\
\cline { 2 - 6 } & Moderate & 3 & $30.0 \%$ & 2 & $20.0 \%$ & \\
\cline { 2 - 6 } & Severe & 0 & $0.0 \%$ & 3 & $30.0 \%$ & \\
\hline \multirow{2}{*}{ Need Surgery } & Improved & 2 & $20.0 \%$ & 3 & $30.0 \%$ & \\
\cline { 2 - 6 } & No need & 7 & $70.0 \%$ & 5 & $50.0 \%$ & \multirow{2}{*}{0.361} \\
\hline
\end{tabular}

Hypotropia in group A improved from 19.4 PD preoperatively to $1.10 \mathrm{PD}$ postoperatively with $\mathrm{P}$-value 0.005 . In group B, it improved from $28.90 \mathrm{PD}$ preoperatively to $11.50 \quad \mathrm{PD}$ postoperatively with $\mathrm{P}$-value 0.004 (Table 4, Figure $1 \& 2$ ). 
Table (4): Comparison between the two studied groups regarding hypotropia of the eye pre and postoperative

\begin{tabular}{|c|c|c|c|c|}
\hline \multirow{2}{*}{\multicolumn{2}{|c|}{\begin{tabular}{|ll} 
Hypotropia (PD) & Groups \\
\end{tabular}}} & Group A & Group B & \multirow{2}{*}{ P-value } \\
\hline & & No. $=10$ & No. $=10$ & \\
\hline \multirow{2}{*}{ Pre-operative } & Mean \pm SD & $19.40 \pm 1.43$ & $28.90 \pm 14.81$ & \multirow{2}{*}{0.111} \\
\hline & Range & $17-22$ & $18-55$ & \\
\hline \multirow{2}{*}{ Post-operative } & Mean \pm SD & $1.10 \pm 1.91$ & $11.50 \pm 14.49$ & \multirow{2}{*}{0.026} \\
\hline & Range & $0-5$ & $0-37$ & \\
\hline \multirow{2}{*}{ Average of corrections } & Mean \pm SD & $18.30 \pm 1.42$ & $17.40 \pm 1.58$ & \multirow{2}{*}{0.196} \\
\hline & Range & $16-20$ & $15-20$ & \\
\hline \multicolumn{2}{|l|}{ P-value } & 0.005 (HS) & 0.004 (HS) & \\
\hline
\end{tabular}

In group B, 3 patients had Knapp's procedure; those 3 cases hypotroia improved by IRR from 50 PD preoperative to $32 \mathrm{PD}$ postoperative then to 3 PD after Knapp's procedure Tables (5 \& 6).

Table (5): Comparison between preoperative and postoperative results regarding hypotropia and Knapp's procedure in group B

\begin{tabular}{|c|c|c|c|c|c|c|}
\hline \multicolumn{2}{|c|}{ Hypotropia (PD) } & Pre & Post & $\begin{array}{c}\text { Average } \\
\text { correction }\end{array}$ & P-value & Sig. \\
\hline \multirow{2}{*}{ Knapp $($ need = 3) } & Mean \pm SD & $50.0 \pm 5.00$ & $32.00 \pm 5.00$ & $18.00 \pm 0.00$ & \multirow{2}{*}{0.03} & \multirow{2}{*}{ 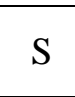 } \\
\hline & Range & & & & & \\
\hline \multirow{2}{*}{ Knapp $($ No need $=7)$} & Mean \pm SD & $19.86 \pm 1.68$ & $2.71 \pm 2.56$ & $17.14 \pm 1.86$ & \multirow{2}{*}{0.017} & \multirow{2}{*}{ S } \\
\hline & Range & $18-23$ & $0-5$ & $15-20$ & & \\
\hline
\end{tabular}

Table (6): Comparison between the results of group B (3 patients) before and after Knapp's procedure

\begin{tabular}{|c|c|c|c|c|c|c|}
\hline \multicolumn{2}{|c|}{ Hypotropia (PD) } & Before Knapp & Post Knapp & $\begin{array}{c}\text { Average } \\
\text { correction }\end{array}$ & P-value & Sig. \\
\hline \multirow{2}{*}{ Knapp (need = 3) } & Mean \pm SD & $32.00 \pm 5.00$ & $3.00 \pm 2.65$ & $29.00 \pm 2.65$ & \multirow{2}{*}{0.009} & HS \\
\cline { 2 - 5 } & Range & $27-37$ & $0-5$ & $27-32$ & & \\
\hline
\end{tabular}

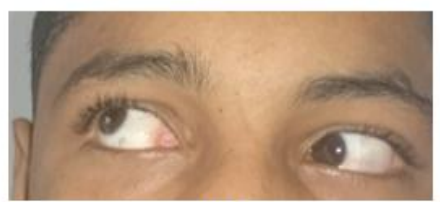

(a)

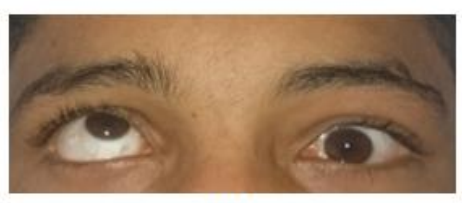

(b)

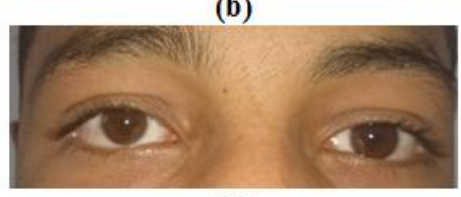

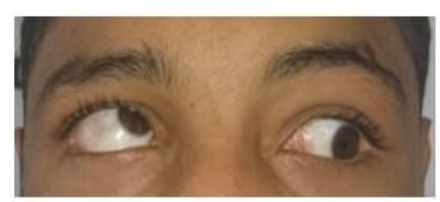

(c)

(d)

Figure (1): Preoperative; Case No. (4) in group A, (a) limited elevation of left eye in adduction, (b) limited elevation of left eye in up gaze, (c)limited elevation of left eye in abduction, (d) hypotropia in primary position. 


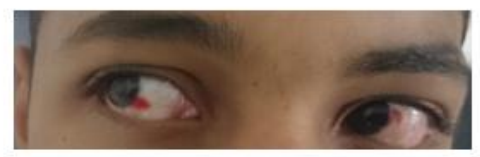

(a)

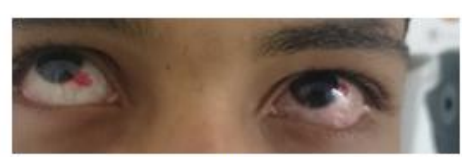

(b)

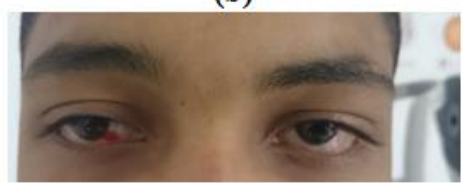

(d)

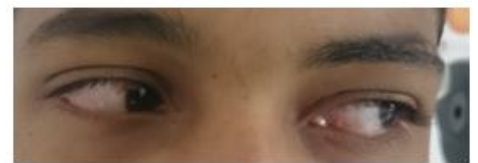

(c)

Figure (2): Postoperative: Case No. (4) in group A, (a) improved elevation of left eye in adduction, (b) improved elevation of left eye in up gaze, (c) improved elevation of left eye in abduction, (d) improved hypotropia in primary position.

\section{DISCUSSION}

In the current study, 20 patients with MED were collected from outclinic in Sayed Galal and El-Hussein University Hospitals. At the period from January 2017 to May 2019. The patients were divided into 2equal groups: Group A with +ve FDT and group B with -ve FDT both groups had IRR. Age, gender, and laterality provided no particular diagnostic information. All cases have ptosis; 25\% had true ptosis, $25 \%$ had pseudo ptosis, $50 \%$ had pseudo and true ptosis. Postoperative $25 \%$ of patients improved completely, $35 \%$ of patients improved with mild ptosis and $40 \%$ of patients had lid surgery. In Talebnejad et al. (2014) $70 \%$ of patients had true ptosis and $30 \%$ of patients had pseudoptosis of studied cases.

In the present study, although IRR markedly improving the elevation of the eye in patients with +ve FDT had limited effectiveness in patients with -ve FDT. Preoperatively, $40 \%$ of patients in group A were -4 (limited elevation), and $60 \%$ of patients were -3 . All those patients improved to -1 (limited elevation) postoperatively. On the other hand, $90 \%$ of patients in group B were -4 and $10 \%$ of patients were -3 . They improved postoperatively to -3 and -2 respectively. Talebenjad et al. (2014) studied 18 patients had MED with different surgical interference according to FDT. The preoperative limitation of up gaze was -2 to -4 (mean -3.5 ) and postoperative was -1 to -3 (mean -1.55). This finding indicated a significant decrease in up gaze limitation.

In the current study, one surgical procedure was used as a 1ry intervention whatever the results of FDT in patients with MED and evaluated the results based on ocular alignment in 1ry position and those with residual significant hypotropia had Knapp's procedure.

In group (A), the average of preoperative hypotropia was $19.40 \pm$ 1.43PD. All the patients had IRR the postoperative average of hypotropia was $1.10 \pm 1.91 \mathrm{PD}$ with average of correction $18.30 \pm 1.42$ PD. The results agree with most reports that studied the results of IRR in MED with + ve FDT as following; Bagheri et al. (2013) the average of correction was $20 \mathrm{PD}$, Talebenjad et al. (2014) the average of correction was 18.6 
and Bandyopadhyay et al. (2016) the average of correction was 16 PD.

In group (B), a reliable and effective correction of hypotropia in $70 \%$ of patients with preoperative mean deviation $19.86 \pm 1.68 \mathrm{PD}$ and postoperative mean deviation $2.71 \pm 2.56 \mathrm{PD}$ with average of correction 17.14 \pm 1.86 PD. Partial correction of hypotropia in $30 \%$ of patients with preoperative mean derivation $50.0 \pm 5.00 \mathrm{PD}$ and postoperative mean deviation $32.00 \pm 5.00 \mathrm{PD}$ with average of correction $32.00 \pm 5.00 \mathrm{PD}$. Then the $30 \%$ of patients underwent Knapp's procedure with postoperative average of correction was $29.00 \pm 2.65 \mathrm{PD}$ This results was in agreement with studies of IRR followed by Knapp's procedure as following; Kocak-Atinatas (2011) the average of correction was 25.8 $\pm 5.6 \mathrm{PD}$, Talebenjad et al. (2014) the average of correction was 26 PD, Bandyopadhyay et al. (2016) the average of correction was 28.6 PD and.

In this study, the effectiveness of Knapp's procedure in correction of vertical deviation increased in eyes with previous IRR. Not only vertical deviation, but also elevation of eye and chin elevation improved. This result was in agreement with Kockak-Altinas (2011). In their study 14 of patients underwent surgery were reviewed $43 \%$ of patients had IRR followed Knapp's procedure and correction of vertical deviation was 25.8 $\mathrm{PD} \pm 5.6 \mathrm{PD}$ and $57 \%$ of patients had Knapp's procedure without IRR and the average of correction was 18.6 PD \pm 4.4 PD. They concluded that surgical effectiveness of transposition surgery may be enhanced by IRR.

Awadein and El-Fayoumi (2015) studied cases with MED with inferior rectus restriction by evaluating the results of ipsilateral inferior rectus recession alone or combined with contralateral superior rectus recession. They found that combined contralateral SR recession with ipsilateral inferior rectus recession achieved better ocular alignment in up gaze and down gaze.

Gundhi and Kekunnaya (2019) who studied patients with MED. IRR were done with single muscle transposition. The average correction was 34.6 PD which considered promising results but this surgical procedure.

Kamlesh and Prolima (2017) studied the efficacy of vertical muscle surgery for management of hypotropia in monocular elevation deficiency (MED) with hypotropia. They found that vertical superior rectus resection and inferior rectus recession are good alternative for management of MED. They spared horizontal muscles for correction of any associated horizontal deviation.

\section{CONCLUSION}

Although the MED is etiologically multifactorial. Satisfactory surgical results can be achieved by IRR as a simple and reliable 1ry intervention for both types (+ve FDT and -ve FDT). IRR is suitable for those patients with hypotropia $<25$ PD. Patients with hypotropia $>25$ PD and -ve FDT usually need Knapp's procedure. Although the IRR in patients with - ve FDT is effective intervention for correcting the alignment of eyes in 1ry position, it still with limited effectiveness in elevation of eye. IRR increased the magnitude of Knapp's procedure.

Conflicts of interest: No conflicts of interest were encountered. 


\section{TAMER TAWHEED MOHAMED et al.,}

\section{REFERENCES}

1. Awadein A and El Fayoumi D (2015): Surgical management of MED combined with inferior rectus restriction. JAAPOS, 19: 316-321.

2. Bagheri A, Sahebghalam $\mathbf{R}$ and Abrishami M (2013): Double elevator palsy, subtypes and outcomes of surgery. Journal of Ophthalmic \& Vision Research, 3: 108-112.

3. Bandyopadhyay R, Shetty $S$ and Vijayalakshmi P (2016): Surgical outcome in monocular elevation deficit: A retrospective interventional study. Indian Journal of Ophthalmology, 56: 127-131.

4. Gandhi U and Kekunnaya R (2019): Single Horizontal Muscle (Medial or Lateral Rectus) Transposition and Inferior Rectus Recession in Monocular Elevation Deficit: A Novel Surgical Technique. Journal of Pediatric Ophthalmology and Strabismus, 56: 183-187.

5. Goray A (2015): Monocular Elevation Deficit-Simplified. The official Scientific
Journal of Delhi Ophthalmological Society; 26:7-13.

6. Kamlesh SD and Prolima T (2017): To Assess the Efficacy of Vertical Muscle Surgery for Management of Hypotropia in Monocular Elevation Deficiency Type II. Int ophthalmol; 37(4): 1009-1016.

7. Kocak-Altintas AG (2011): Selective management of double elevator palsy by either inferior rectus recession and/or knapp type transposition surgery. Binocular Vision \& Strabismus Quarterly, 15: 39-46.

8. Saluja G and Bhari A (2019): Monocular elevation deficit after scleral perforation repair. BMJ case reports CP; 10:129-133.

9. Talebnejad MR, Roustaei GA and Khalili MR (2014): Monocular elevation deficiency: a case series of surgical outcome. Iranian Journal of Medical Sciences, 39:102-105.

10. Zafar SN, Azad N and Khan A (2012): Outcome of surgical treatment of MED: J Pak Med Assoc, 62: 355-337. 


\section{تقييم إرجاع العضلة المستقيمة السفلية في علاج إضراب رفع الإن

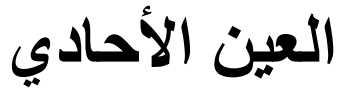

تامر توحيذ محمد عبدالسلام، عطيات مصطقي السيد مصطقي، محمود محمد صالح. قسم طب وجراحه العيون، كليه الطب، جامعة الأزهر، القاهره، مصر

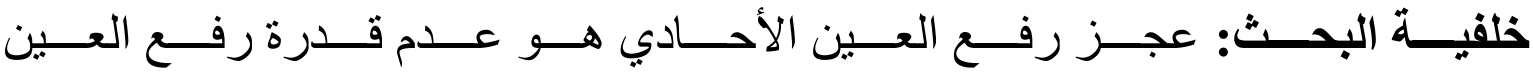
المصابة لأعلي.

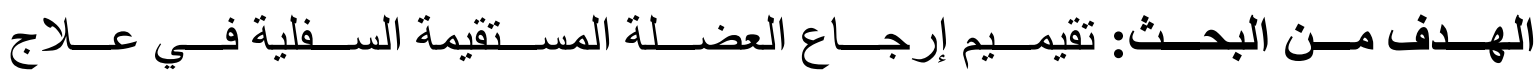

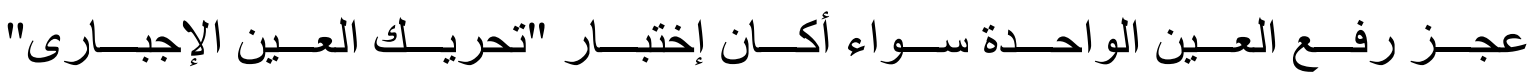
إيجابى أو سلبي.

المرضــــي وطــــرق البحـــث: أجريـــت هـــذه الدر اســــة علــى 20 مـــريض مـــن

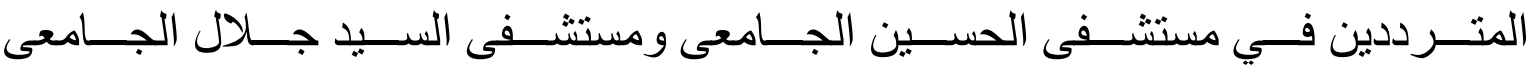

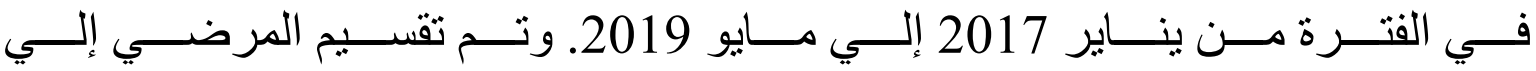

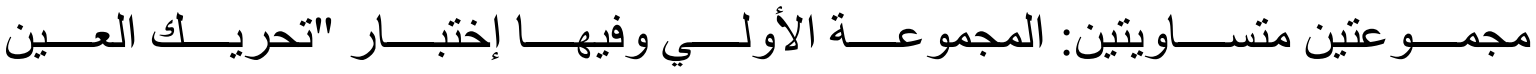

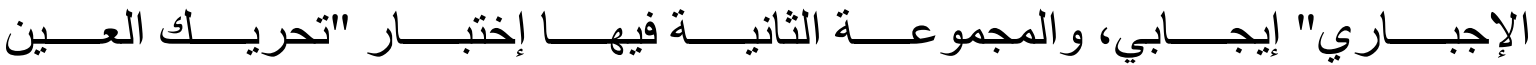

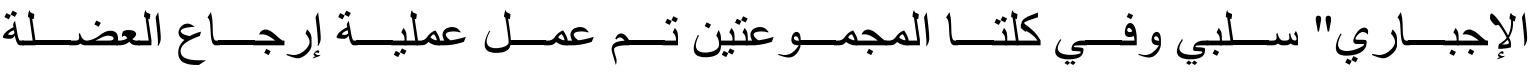

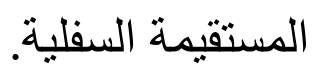

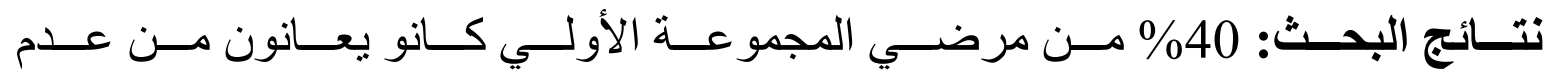

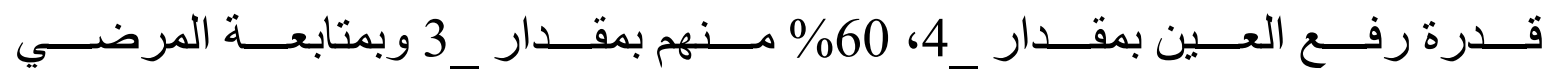

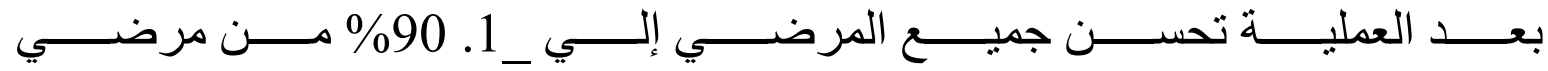

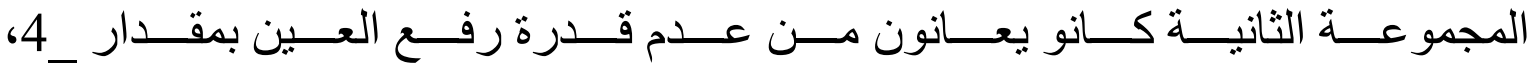

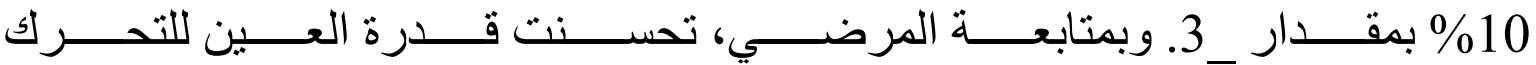

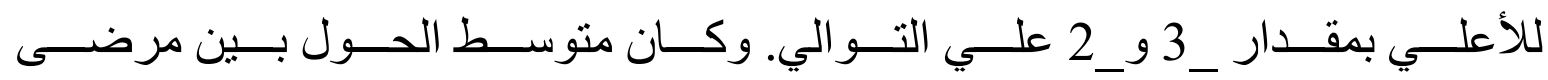

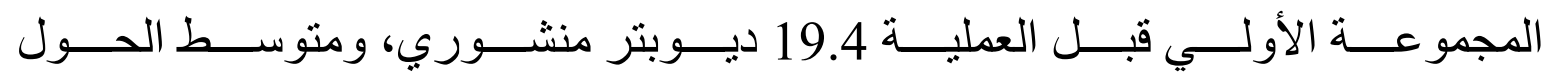




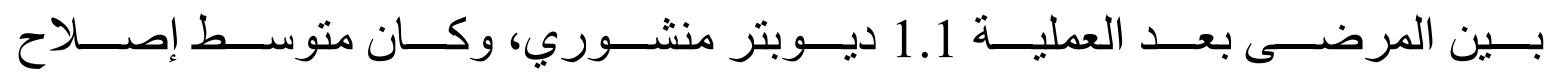

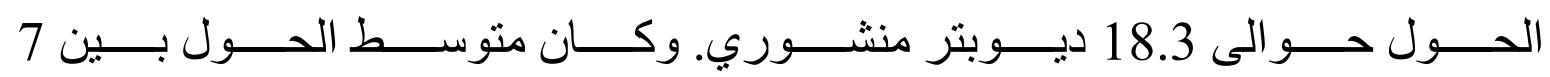

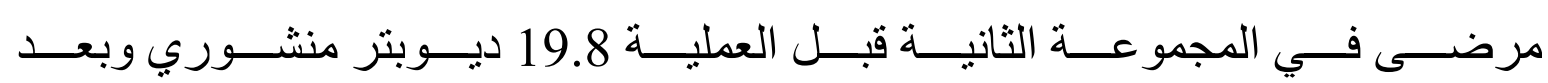

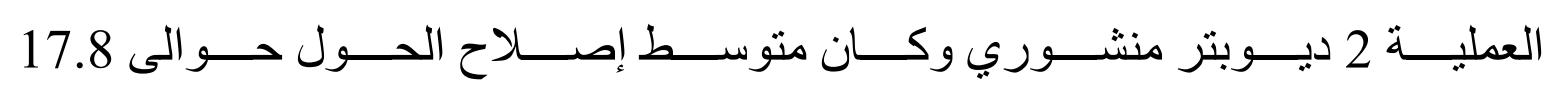

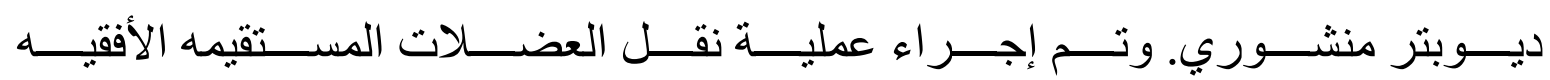

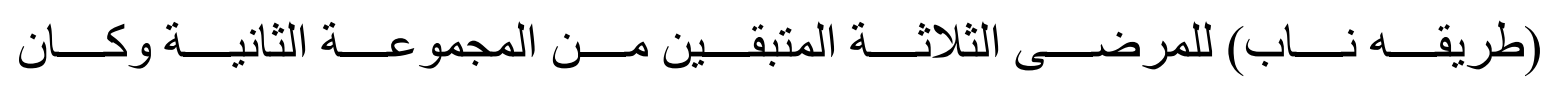
منوسط إصلاح درجة الحول 29 ديوبتر منشوري.

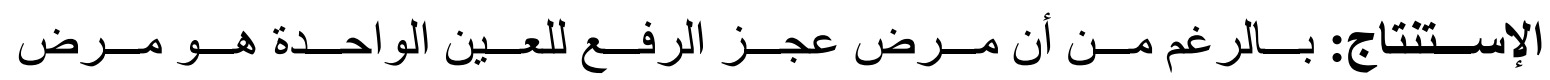

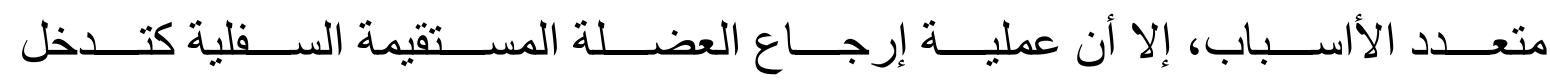

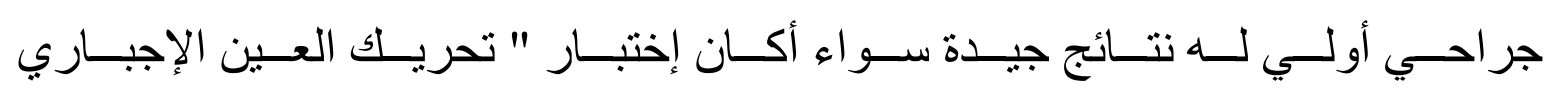

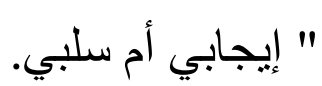

